\section{HOMOZYGOSITY FOR HLA-C2 ALLELES IS NEGATIVELY ASSOCIATED WITH TREATMENT RESPONSE WITH PEGLYATED INTERFERON- $\gamma$ AND RIBAVIRIN IN HEPATITIS C GENOTYPE 1 INFECTED INDIVIDUALS}

M Collison, ${ }^{1}$ J L Chin, ${ }^{2}$ A Abu Shanab, ${ }^{2}$ R MacNicholas, ${ }^{2}$ J Connell, ${ }^{1}$ M Carr, ${ }^{1}$ W Hall, ${ }^{1}$ P A McCormick ${ }^{1}$ National Virus Reference Laboratory, University College Dublin, Belfield, Dublin 4, Ireland; ' 2 Liver Unit, St Vincent's University Hospital, Dublin 4, Ireland

\subsection{6/gutjnl-2013-305143.10}

Introduction Standard therapy for chronic hepatitis C virus (HCV) infection consists of pegylated interferon-? and ribavirin. This treatment is only effective in $40-50 \%$ of patients with HCV genotype 1 (G1) infections. The IL28B single nucleotide polymorphism (SNP) is well described but other host genetic factors may influence treatment response.
Table 2 HLA-C type of HCV genotype 1 and 3 responders and non-responders

\begin{tabular}{lllll}
\hline Genotype & Response & $\begin{array}{l}\text { HLA-C1/C1 } \\
\text { homozygous }\end{array}$ & $\begin{array}{l}\text { HLA-C1/C2 } \\
\text { homozygous }\end{array}$ & $\begin{array}{l}\text { HLA-C2/C2 } \\
\text { homozygous }\end{array}$ \\
\hline \multirow{2}{*}{ HCV genotype 1 } & Responders & 19 & 15 & 0 \\
& Non-responders & 19 & 11 & 7 \\
HCV genotype 3 & Responders & 13 & 26 & 5 \\
& Non-responders & 13 & 9 & 1 \\
\hline
\end{tabular}

Aims/Background This study investigated associations between host genetic variation and treatment response to standard therapy in HCV genotype 1 and 3 (G3) infected patients. The genetic markers investigated comprised four IL28B SNPs (G1 $\mathrm{n}=89 ;$ G3 $\mathrm{n}=82)$ : $\mathrm{rs} 12979860, \quad \mathrm{rs} 8099917, \quad \mathrm{rs} 4803221$, rs7248668; and HLA-C alleles (G1 n=71; G3 n=67): C1/C1, $\mathrm{C} 1 / \mathrm{C} 2$ or $\mathrm{C} 2 / \mathrm{C} 2$.

Method Nucleic acids were extracted from serum and plasma and SNP typing was performed by allelic discrimination realtime PCR, PCR-SSP and sequencing approaches.

Results For HCV genotype 1 infections, the IL28B SNP rs12979860 was the most significant genetic marker for predicting non-response to treatment, with a positive predictive value of $81.3 \%$ in patients homozygous for the T allele. HLA-C2 homozygosity was found to be significantly associated with non-response in genotype 1 infections $(p=0.023) .19 \% \quad(7 / 37)$ of nonresponders were HLA-C2/C2 homozygoytes compared to no patients (0/34) with this genotype who achieved SVR. All HCV genotype 1 patients homozygous for HLA-C2, who did not achieve SVR, were rs12979860 heterozygotes (C/T). For HCV genotype 3 patients, no significant association was observed between HLA-C and non-response to treatment $(p=0.09)$.

Prediction measures were calculated using non-response as the outcome of interest, and each genetic variant as the "test" for non-response. The * notation refers to all genotypes containing that allele.

Conclusion A combination of IL28B rs12979860 and HLA-C host genotype may better predict treatment outcomes to standard therapy for HCV genotype 1 infections.

Table 1 Predictive values of the IL28B genetic variants in HCV genotype 1 and HCV genotype 3-infected individuals receiving standard therapy.

\begin{tabular}{|c|c|c|c|c|c|c|c|}
\hline Viral Genotype & Host marker & Reference variant & Risk variant & Specificity\% & Sensitivity\% & PPV\% & NPV $\%$ \\
\hline \multirow[t]{8}{*}{ Gen 1} & rs12979860 & $C^{*}$ & TT & 93.5 & 30.2 & 81.3 & 58.9 \\
\hline & & CC & $T^{*}$ & 52.2 & 83.7 & 62.1 & 77.4 \\
\hline & rs 4803221 & $C^{*}$ & GG & 95.7 & 14.0 & 75.0 & 54.3 \\
\hline & & $\mathrm{CC}$ & $\mathrm{G}^{*}$ & 63.0 & 69.8 & 63.8 & 69.0 \\
\hline & rs8099917 & $T^{*}$ & GG & 95.7 & 14.0 & 75.0 & 54.3 \\
\hline & & TT & $\mathrm{G}^{*}$ & 63.0 & 67.4 & 63.0 & 67.4 \\
\hline & rs7248668 & $\mathrm{G}^{*}$ & AA & 95.7 & 14.0 & 75.0 & 54.3 \\
\hline & & GG & $A^{*}$ & 60.9 & 65.1 & 60.9 & 65.1 \\
\hline \multirow[t]{8}{*}{ Gen 3} & rs12979860 & $C^{*}$ & TT & 91.2 & 4.0 & 16.7 & 68.4 \\
\hline & & $\mathrm{CC}$ & $T^{*}$ & 47.4 & 52.0 & 30.2 & 69.2 \\
\hline & rs 4803221 & $C^{*}$ & GG & 98.2 & 0.0 & 0.0 & 69.1 \\
\hline & & $\mathrm{CC}$ & $\mathrm{G}^{*}$ & 61.4 & 44.0 & 33.3 & 71.4 \\
\hline & rs8099917 & $T^{*}$ & GG & 98.2 & 0.0 & 0.0 & 69.1 \\
\hline & & TT & $\mathrm{G}^{*}$ & 61.4 & 44.0 & 33.3 & 71.4 \\
\hline & rs7248668 & $\mathrm{G}^{*}$ & AA & 98.2 & 4.0 & 50.0 & 70.0 \\
\hline & & GG & $A^{*}$ & 63.2 & 44.0 & 34.4 & 72.0 \\
\hline
\end{tabular}




\section{Abstracts}

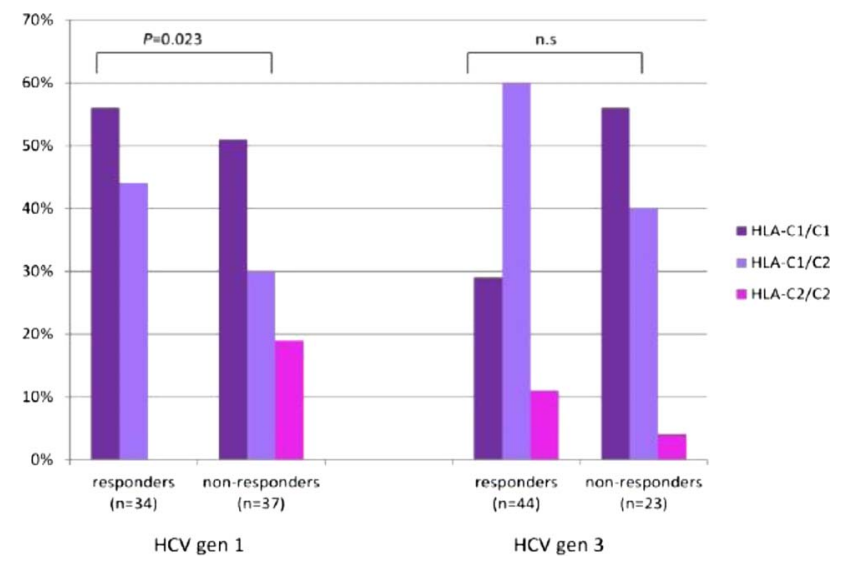

Figure 1 Frequency of HLA-C1/C2 in HCV genotype 1 and 3 responders versus non-responders. 


\section{Corrections}

Collison M, Chin JL, Abu Shanab A, et al. Homozygosity for hla-c2 alleles is negatively associated with treatment response with peglyated interferon- $\gamma$ and ribavirin in hepatitis c genotype 1 infected individuals. Gut 2013;62(Suppl 2):A5. doi: 10.1136/gutjnl-2013-305143.10.

There was an atypographical error in the title, which reads "peglyated" instead of "pegylated". In addition, we have noticed two further errors, one in the title and one in the Introduction of the abstract. In the title, 'interferon- $\gamma$ ' should read 'interferon- $\alpha$ '. In the Introduction, 'interferon-?' should read 'interferon- $\alpha$ '.

Gut 2013;62:1432. doi:10.1136/gutjnl-2013-305143.10corr1 